\title{
A Review of Codes and Standards for Bamboo Structural Design
}

\author{
Ermias A. Amede $\mathbb{D}^{1}{ }^{1}$ Ezra K. Hailemariama, ${ }^{1}$ Leule M. Hailemariam, ${ }^{2}$ \\ and Denamo A. Nuramo ${ }^{1}$ \\ ${ }^{1}$ Construction Management, Addis Ababa University, Addis Ababa, Ethiopia \\ ${ }^{2}$ Structural Engineering, Addis Ababa University, Addis Ababa, Ethiopia
}

Correspondence should be addressed to Ermias A. Amede; ermiasdjcuzo@gmail.com

Received 7 May 2021; Accepted 22 October 2021; Published 31 October 2021

Academic Editor: Antonio Gloria

Copyright (c) 2021 Ermias A. Amede et al. This is an open access article distributed under the Creative Commons Attribution License, which permits unrestricted use, distribution, and reproduction in any medium, provided the original work is properly cited.

\begin{abstract}
Bamboo is a strong, fast-growing, and sustainable material. In modern times, it can be an aesthetically pleasing and low-cost alternative to more conventional materials. Despite the literature's consideration of bamboo's promising potential as a resilient, sustainable building material for structural element design, its application is limited. This is mainly due to the limited availability of universally applicable standards and codes to guide or assist in developing the structural element design. As a result, bamboo as an engineering material was mainly dependent on established practical traditions, intuitions of forbears, and engineering experience. This paper reviewed available structural element design standards and codes of practice. Based on the literary works, it was possible to conclude that there is a need to develop a comprehensive universally applicable bamboo design, construction standards, and code of practices, addressing several social and trade benefits as well as engineering recognition and enhanced status of bamboo as an engineering material.
\end{abstract}

\section{Introduction}

The use of bamboo in several countries trend revealed it had been utilized for over hundreds of years in almost all aspects of their lives: for cooking utensils, working tools in the field, furniture, and, of course, as a building material $[1,2]$. Archaeological remains indicate that bamboo has been used for housing in the Ecuadorian region for thousands of years. In South American countries, the natives used bamboo intensively before the arrival of the European invaders who never knew how to use Bamboo [3, 4]. However, until the 1980 s, its use was limited to the construction of scaffolding and simple dwellings.

Recently, some literary works have indicated that bamboo can be used for more than just housing construction. It can also be used for bridges (bamboo bridges, however, are generally of trestle construction and of limited span for carrying only light (usually pedestrian) traffic. Simple trussed constructions have also been built and have been shown capable of supporting substantial loads), scaffolding, bamboo-reinforced concrete (bamboo exhibits certain characteristics which limit its effectiveness as concrete reinforcement, and considerable research effort continues to be directed at this subject), bamboo-based panels, and aesthetical purposes in modern building constructions as illustrated in Figures 1 and 2. This is mainly because of bamboo's species adaptability in a variety of ecological environments (bamboo can grow in several areas ranging from tropical lowland to highland, from rain forest in tropical countries to deserts, and from acid to alkaline soils), its ability to repair soil devastation, its ripeness to be harvested after 3 to 5 years of plantation, its capacity to produce a cost-efficient, high-quality bamboo culm suitable for use as a wood supplement, and its versatility possessing high strength-to-weight ratio, which offers considerable ease in working with more straightforward tools [5]. Furthermore, bamboo's resilience coupled with lightweight makes bamboo an ideal material for housing in disasterprone/earthquake-prone areas. Bamboo can withstand repetitive loadings, absorb more energy, and show more 


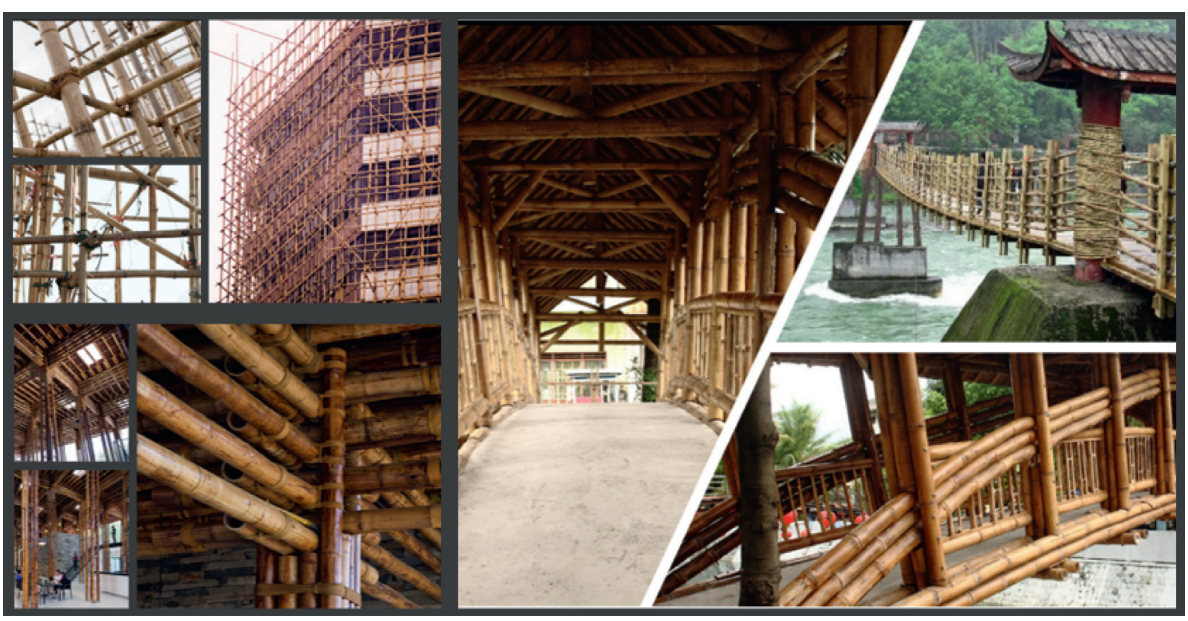

Figure 1: Bamboo as a structural element.
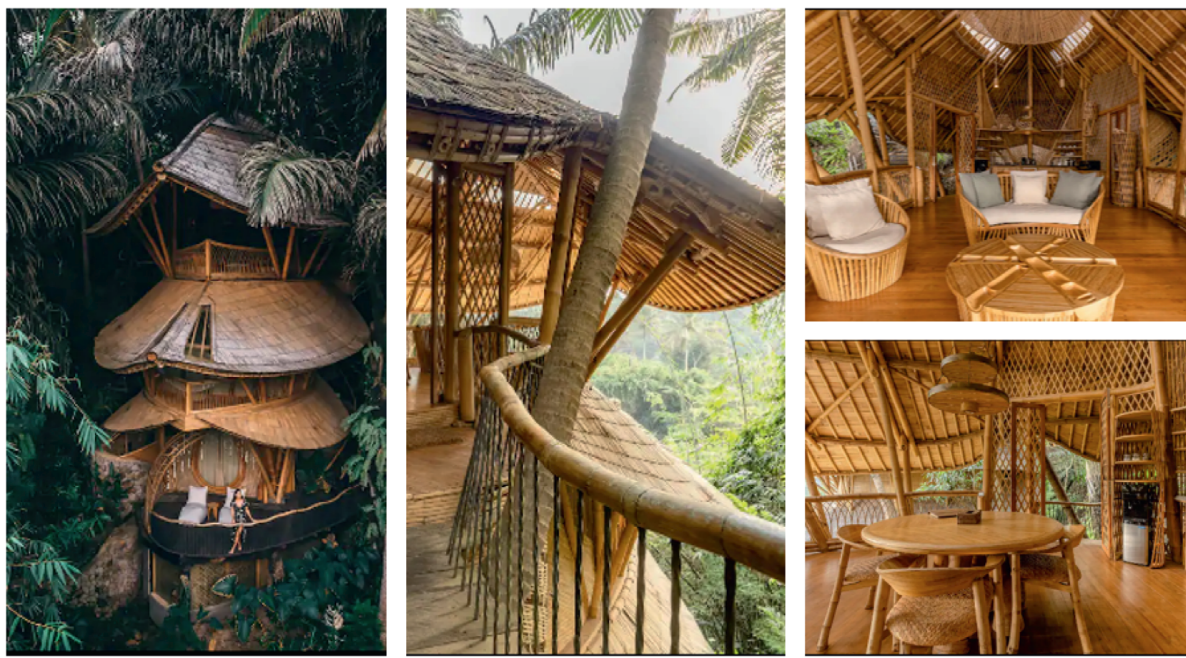

Figure 2: Aura House, 2bds eco bamboo house.

considerable deflections before collapsing, and as such, it is safer under Earth tremors. As a result of the conveniences mentioned above, there is driving interest in developing bamboo as a sustainable material in contemporary buildings to reach the growing urban demand.

One of the most common challenges in designing structural design elements using bamboo is comparing bamboo's physical and mechanical properties due to the inadequacy of a standardized and codified measurement framework. Nevertheless, numerous studies on the physical and mechanical properties of bamboo have been commenced worldwide. Comparing the test results poses a challenge as the testing protocol obeys different criteria. In most cases, researchers prefer to use timber test protocols; this practice makes a comparison of test results difficult [6].

This study was inspired by reaping bamboo's versatility and adaptability as a potential alternative material for the construction industry. Before utilizing conventional materials for construction, especially in structural design elements, it is astute to have a well-established scientific backing that can validate the design. This calls for having internationally accepted standards for structural element design. Hence, this paper reviewed the availability of adequate structural design codes and standards for applying bamboo to the construction industry.

\section{Review of the State of the Art}

2.1. Standard and Code of Practice. The basic description of codes and standards is commonly confusing and used interchangeably: but for this paper's purpose, it is astute to contemplate the fundamental differences they have. "A code tells you what you need to do, and a standard tells you how to do it [7]."

Standardization is founded on the concerted involvement of construction stakeholders, who collectively embrace and promote the standardization process [1]. Based on a literature review, an international standardization and codification for bamboo construction is needed for the material to be accepted as a sustainable structural and construction material by both designers and policymakers worldwide $[8,9]$. Furthermore, expectations create a 
demand for improved technologies that would be commercially unsuccessful otherwise [10]. This is because standards provide a means to maintain product quality and cover technical details, such as test procedures, that building codes can cite.

\subsection{Existing Standards for Bamboo Structural Element Design.} A standard serves as a common language for defining quality and establishing product safety criteria regarding materials, craft, and structures [6]. It could be a compilation of technical principles and instructions for designers and manufacturers, or it could just be a "how-to" manual. It also provides all necessary product, service, and process specifications that allow engineers to achieve common engineering or technical requirements, create customer trust in product quality, and reduce production costs through standardization by manufacturing in bulk for global markets.

Standardization of construction materials and practices serves both technical and social purposes. The objective of a standard material test procedure, for instance, is to determine the design value of the material accurately (e.g., strength and stiffness) as well as to provide a typical frame of reference for the user community. Data from such comparable tests can be compiled to obtain a more reliable understanding of a material's properties based on statistical analysis, leading to the refinement of and confidence in the design values, leading to broader acceptance of the design community's material. Such acceptance, coupled with advocacy, can lead to broader social acceptance of previously marginalized vernacular construction methods.

The effort to develop bamboo material utilization standards as a building and structural element had started in the late 20th century. The Bureau of Indian Standards introduced the first method of testing standard for round bamboo, IS: 6874 , to realize the mechanical properties of bamboo in 1973; following that in the late 1990s, a series of test standards for round bamboo were conducted in the Eindhoven University of Technology with the name of International Network for Bamboo and Rattan (INBAR) that lays a foundation for the development of ISO 22156, ISO 22157-1 (Bamboo-Determination of Physical and Mechanical Properties-Part 1: Requirements), and ISO 22157-2 (Bamboo-Determination of Physical and Mechanical Properties-Part 2: Laboratory Manual) which were published in 2004 by the International Organization for Standardization (ISO) and recorded as the first step to standardize the utilization of bamboo for a structural design element [1]. Even though ISO was instrumental in bringing bamboo's application for structural design to the world, the "AC 162-Acceptance for Structural Bamboo" document issued by the International Conference of Building Officials in California in 2000 was the very first document enabling the use of bamboo as a structural material.

Years down the road, the field has advanced due to increased global interest and research. However, the need for more standardization is still being refined through the work of universities, laboratories, and professional organizations
$[1,10,11]$. Countries with abundant bamboo resources, such as China, Colombia, Ecuador, India, and Peru, have pioneered bamboo construction codes and standards [12]. The available codes and standards for structural design and construction with bamboo are summarized in Tables 1 and 2 and reviewed in the following sections.

\subsection{International Organization for Standardization (ISO).} In 2004 International Organization for Standards (ISO) published essential design guidance for whole-culm construction (ISO 22156). Additional standards were passed in September 2018 with ISO 19624 : 2018, detailing the grading procedures for visually and mechanically sorting bamboo poles for structural applications.

2.3.1. ISO 22156 Bamboo: Structural Design. As a result of the significant developments taking place in code development and research throughout the world since the first version publication of ISO 22156 in 2004, it was therefore considered appropriate to be updated and changed from a design theory code to a template standard that various countries could implement according to their species and practices. Hence, the new updated ISO 22156 ensured its compliance with the new ISO bamboo standards ISO 19624 and ISO 22157. However, it will continue to borrow from timber standards to derive characteristic values, connection testing, and shear wall testing. These standards are well suited for testing any natural lignocellulosic material and are not prescriptive in element shapes or sizes. In many other respects, ISO 22156 will pick up where G.12 left off.

ISO 22156 stated a limitation of the applicability of the standard in a similar situation, or special attention should be given to differences between material originating from different localities. This standard employs the basic design concept that construction design calculation shall not exceed the relevant limit state or no relevant permissible stress is exceeded. Limit states are states beyond which the structure no longer satisfies the design performance requirements.

In this standard, the characteristics values are determined based on the assumption of a linear relationship between stress and strain until failure. The strength verification of individual members shall also be based on such a linear relation. The standard notes that the strength and stiffness parameters shall be determined based on the action effects to which the material will be subjected to the structure. Calculating the action effects on the structure shall be assessed with a linear material model (elastic behavior).

The design stress calculation in this standard is recommended to have the same calculation with timbers. The following design requirements must be met before a structure made of bamboo can be built: (a) It shall be verified that no relevant limit state is exceeded. All relevant design situations and load cases shall be considered. Possible deviations from the assumed directions or positions of action shall be considered. (b) Calculations shall be performed using appropriate design models (supplemented, if necessary, by tests) involving all relevant variables. (c) The 
TABLE 1: Codes for bamboo structural design.

\begin{tabular}{|c|c|c|}
\hline Country & $\begin{array}{c}\text { Year of } \\
\text { publication }\end{array}$ & Code name \\
\hline Colombia & 2010 & $\begin{array}{c}\text { Reglamento Colombiano de Construcción Sismoresistente-chapter G.12 Estructuras de Guadua (Guadua } \\
\text { Structures) }\end{array}$ \\
\hline China & 2011 & JGJ 254: Technical code for the safety of bamboo scaffold in construction \\
\hline Ecuador & 2011 & $\begin{array}{l}\text { Norma Ecuatoriana de la Construcción-chapter } 17 \text { Utilizacio' n de la Guadua Angustifolia Kunth en la } \\
\text { Construcción (Use of Guadua angustifolia Kunth in construction) [13] }\end{array}$ \\
\hline India & 2005 & $\begin{array}{c}\text { The National Building Code of India-developed a Code of Practice for Bamboo Design-Section 3-Timber } \\
\text { and Bamboo: 3B }\end{array}$ \\
\hline & 1979 & 9096: Code of practice for preservation of bamboo for structural purposes \\
\hline Peru & 2012 & $\begin{array}{l}\text { Reglamento Nacional de Edificaciones, Section 3. Code E100- Diseño y Construcción con Bamboo (ICG) } \\
{[14]}\end{array}$ \\
\hline
\end{tabular}

TABLE 2: Standards for bamboo structural design.

\begin{tabular}{|c|c|c|}
\hline Country & $\begin{array}{c}\text { Year of } \\
\text { publication }\end{array}$ & Code name \\
\hline \multirow{4}{*}{ International } & 2004 & ISO 22156 Bamboo-Structural Design \\
\hline & 2004 & $\begin{array}{l}\text { ISO 22157-1 Bamboo-Determination of Physical and Mechanical Properties-Part 1: Requirements } \\
\text { (ISO, 2004b) ISO }\end{array}$ \\
\hline & 2004 & $\begin{array}{c}\text { ISO 22157-2: Bamboo-Determination of Physical and Mechanical Properties-Part 2: Laboratory } \\
\text { Manual }\end{array}$ \\
\hline & 2018 & ISO 19624 Bamboo structures-Grading of Bamboo Culms-Basic Principles and Procedures \\
\hline \multirow{5}{*}{ China } & 2014 & JG/T 428: Composite ply bamboo form with steel frame \\
\hline & 2014 & GB/T 30762: Quality grading standards of main bamboo shoot \\
\hline & 2007 & JG/T 199: A testing method for physical and mechanical properties of bamboo used in building [15] \\
\hline & 2000 & GB/T 2690-Bamboo timber \\
\hline & 1995 & GB/T 15780: Testing methods for physical and mechanical properties of bamboo \\
\hline \multirow{6}{*}{ India } & 2012 & IS 6874: Method of tests for bamboos \\
\hline & 2010 & IS 6874: Method of tests for round bamboos [16] \\
\hline & 2008 & IS 6874: Method of tests for round bamboos [17] \\
\hline & 1994 & 13958: Specification for bamboo mat board for general purposes \\
\hline & 1976 & 8242: Method of test for split bamboo \\
\hline & 1973 & IS:6874: Method of test for round bamboo \\
\hline \multirow[t]{2}{*}{ Colombia } & 2007 & $\begin{array}{c}\text { NTC 5525: Me' todos de Ensayo para Determinar las Propiedades Físicas y Meca' nicas de la Guadua } \\
\text { angustifolia Kunth (methods and tests to determine the physical and mechanical properties of Guadua } \\
\text { angustifolia Kunth) }\end{array}$ \\
\hline & 2006 & $\begin{array}{c}\text { NTC 5407: Uniones de Estructuras con Guadua angustifolia Kunth (structural unions with Guadua } \\
\text { angustifolia Kunth) }\end{array}$ \\
\hline Ecuador & 1976 & INEN 42: Bamboo Caña Guadua (bamboo cane Guadua) \\
\hline USA & 2013 & ASTM D5456: Standard specification for evaluation of structural composite lumber products \\
\hline
\end{tabular}

verification of limit states and the partial safety factors shall be according to relevant national standards. (d) The loads and actions to be considered in the calculations shall be according to relevant national standards.

\subsubsection{ISO 22157 Bamboo Structures: Determination of} Physical and Mechanical Properties of Bamboo Culms-Test Methods. Compared to the preceding one, the revised ISO 22157 has been dramatically simplified. Two mechanical tests were added-one physical test (shrinkage) was removed, and procedures to ensure proper consistency and accuracy were given further thought. Consideration was also given to the phase of homogenization, which is that all ISO standards are comparable. The outcome standard is more closely compatible with current requirements for wood research. However, it acknowledges the technical constraints that some bamboo scientists might have and is written to complement ISO 19624 well.

The ISO 22157 standard for bamboo structural design includes tests to determine strengths in compression parallel to the fibers, flexure, shear, and tension parallel to the fibers. In the testing method of characteristics of bamboo for structural designs, the sample must be fully representative of the variability of the material proposed to be used for the actual structure. The variability in sample selection should include origin, age, and position along the culm. Nonetheless, the minimum sample size stated in the standard is 12; the sample size required depends on the variability (species) in the actual structure. Increasing the sample size helps increase confidence and understand of the species so that the design value will be less penalized. This standard focus of testing shall be given to the bending and shear tests than tension and compression tests. This standard indicates 
that if bamboo dries below the saturation point of the fiber, it will increase in strength.

The standard ISO 22157-1 [18] also contains a procedure to determine density at discrete locations; however, as density varies along the culm [10], this procedure was deemed of limited value. It was adopted for a density estimation based on a representation of the culm as a hollow cylinder.

\subsubsection{ISO 19624 Bamboo Structures: Grading of Bamboo} Culms-Basic Principles and Procedures. Alternative grading procedures can be needed as bamboo is not available in a modularized size. ISO 19624 is merely a structure through which grading procedures can be developed; it is not a guide to these procedures. Grading can be done according to the source material (e.g., bamboo species and plantation) or according to the end-user (i.e., what we want to use it for).

In this standard, grading is described as "the method of sorting each piece of bamboo in a sample into grades under outlined selection criteria." The grading rules should be based on characteristics known to affect bamboo elements' strength or load-bearing capacity. The ISO standard (19624) proposes that these characteristics are divided into conditional, geometric, and dimensional properties. It defines them as follows: "conditional properties refer to the state of the material in terms of moisture content, age at the time of harvesting, insect and fungal damage, and defects such as fissures and longitudinal indentation. Dimensional properties refer to diameter, wall thickness, internodal length, and culm length. Geometrical properties refer to bow, taper, and ovality."

\subsubsection{BS ISO/NP 23478: Bamboo Structures-Glued Laminated} Bamboo-Test Methods for Determination of Physical and Mechanical Properties. The number of potential structural applications for bamboo culms is limited due to the circular hollow section design of the bamboo culm and the range of available sizes. As a mitigation measure for the limited range of structural applications, ISO/NP 23478 developed a standard called Engineered Bamboo Products to broaden the scope of bamboo's application (EBPs) as shown in Figure 3. Via modularizing, EBPs product that can be designed to be more durable and fire-resistant than bamboo culms

2.4. China. As a result of increased investigation and research on bamboo construction, the China National Standards established about eighty-six (86) standards related to bamboo materials ranging from harvesting to quality assurance in several aspects.

Full culm bamboo standards like JG/T 199 (2007): a testing method for physical and mechanical properties of bamboo used in buildings provides guidance for material and mechanical testing. This standard covers the physical and mechanical tests found in ISO 22156 [19], although the methods and testing conditions are different. For example, JG/T 199 uses parts of the culm wall for all mechanical tests. In contrast, the ISO standard uses the whole culm for compression, shear, and flexure tests. The Chinese standard also uses different measures to achieve the modulus of elasticity in compression, tension, and flexure. JG/T 199 includes a correction factor, which utilizes an analytical equation to account for moisture content in the specimen to obtain strength and stiffness values.

The standard mentioned above for design element construction is not the only one published by China Building and Construction Standards concerning bamboo construction. Here are a few more: JG/T 428-2014-Composite ply bamboo form with steel frame, JGJ 254-2011-Technical code for the safety of bamboo scaffold in construction. Moreover, here are some of the standards that can be referred for a design of structural elements, which was initially published in China National Standards: GB/T 26902000-Bamboo timber, GB/T 30762-2014-Quality grading standards of main bamboo shoot, and GB/T 157801995-Testing methods for physical and mechanical properties of bamboo.

\subsection{India}

2.5.1. Structural Design Using Bamboo-Code of Practice (First Revision of IS 15912). The Indian standard of bamboo for structural construction involves several components, such as the general principles involved in the design of structural bamboo in buildings in terms of mechanical resistance and structural durability. This standard involves the construction of bamboo (round bamboo, split bamboo, and glued laminated bamboo) and bamboo-based panels joined together with adhesives or mechanical fasteners as illustrated in Figure 4. It also includes minimum strength details, dimensional stability, grading specifications, and traditional bamboo joints for quality assurance. In addition to the steps required to define and ensure the quality of the material and working standards to comply with the criteria and limitations of the design codes, construction aspects such as work on-site, parts manufacturing, and installation are included.

The following elements are not covered by the structural design using bamboo-code of practice standards: (a) limit state design and structure performance and (b) scientific design of bamboo joints and fastenings. This standard categorizes the tested and recommended bamboo species into three groups based on their strength properties: specifical modulus of elasticity (E), modulus of rupture (R), and compressive strength.

The founding principle of bamboo grading for structural application is its strength and stiffness properties. Based on one or a combination of the following parameters, the standard provides a grading of bamboo for structural utilization: (a) diameter and length of the culm; (b) taper of the culm; (c) straightness of culm; (d) internodal length and distribution of nodes; (e) wall thickness; (f) density and strength; and (g) durability and seasoning. From the report of tests included in the standard, the strength of bamboo increases as the moisture content decreases. The optimum moisture content of fiber saturation point for most bamboos is around 25 percent; however, it depends on the species. The measurement methods for moisture content are in 


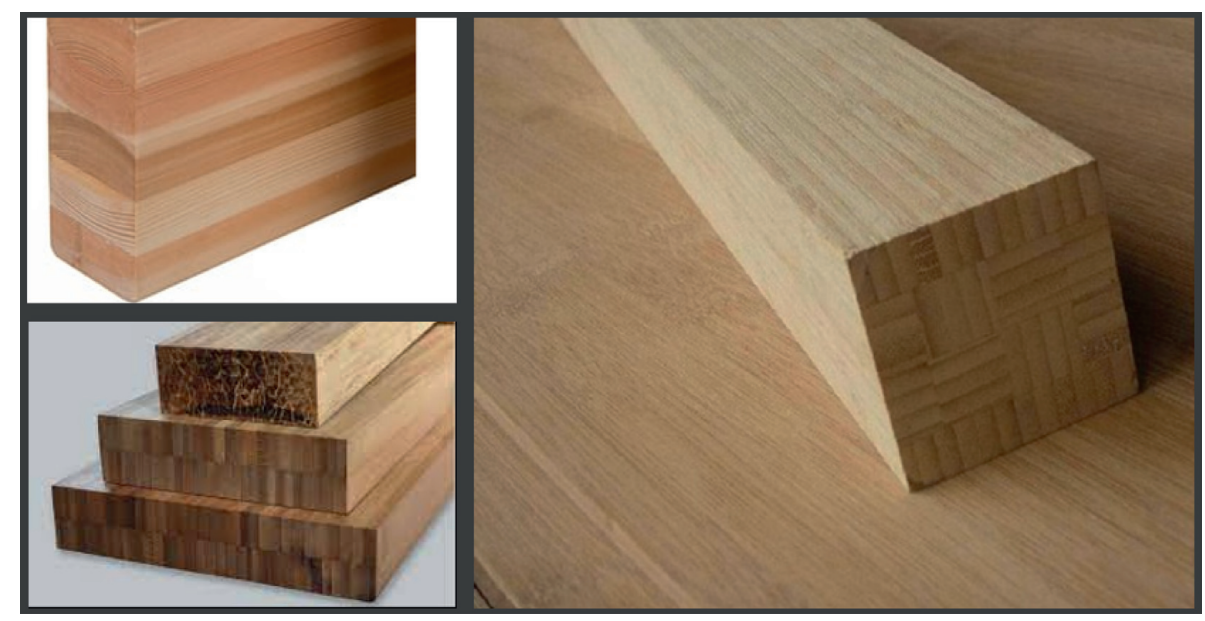

FIgURE 3: Engineered bamboo products.

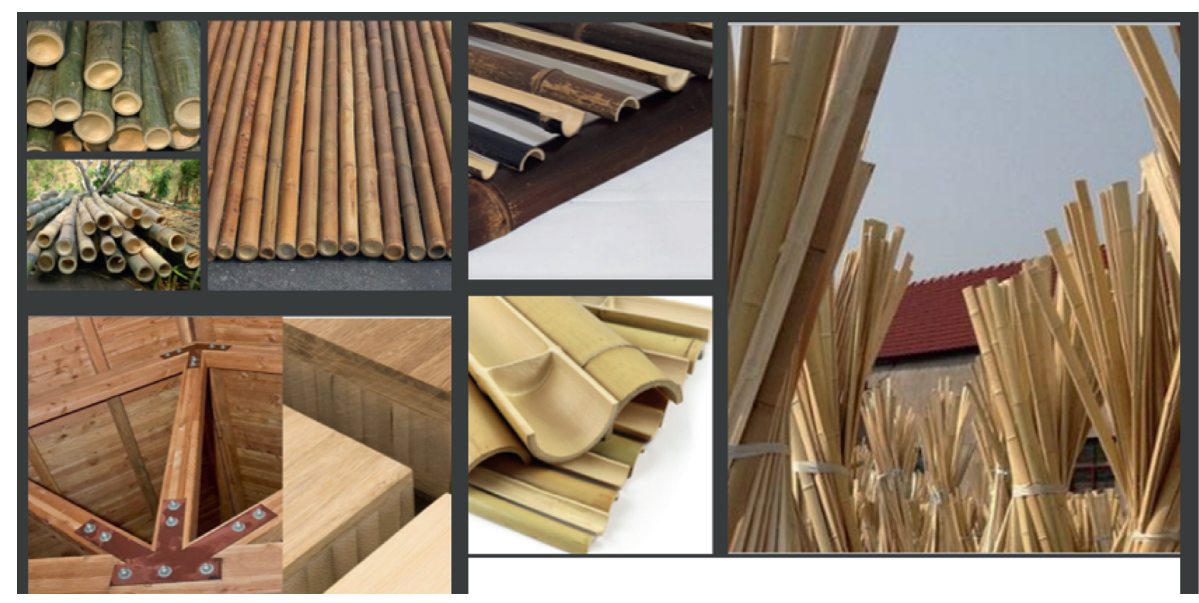

Figure 4: Round, split, glued laminated, and mechanically fastened bamboo.

accordance with IS 6874: method of tests for bamboo. Generally, the standard noted that matured culms should be seasoned to about 20 percent moisture content before use.

2.6. Colombia. Colombians have also developed a standard of bamboo for utilization in constructions like NTC 5407, on structural joints with Guadua angustifolia Kunth [20], and NTC 5525 (on methods and tests to assess the physical and mechanical properties of Guadua angustifolia Kunth), which are two other Colombian standards [21].

2.7. Ecuador. The INEN 42 advocates the benefits of bamboo as a building material in Ecuador, but it lacks design guidance [22].

\subsection{USA}

2.8.1. ASTM D5456. Standard specification for evaluating structural composite lumber products (ASTM 2013) is the first to recognize laminated veneer bamboo as a structural product and provide guidance on manufacturing standards and test methods [1]. Material is treated as an equivalent to structural composite lumber products such as laminated strand lumber, laminated veneer lumber, oriented strand lumber, and parallel strand lumber [23].

\subsection{Existing Code of Practices for Bamboo Structural Element} Design. A standard becomes a code for practice when implemented by public agencies and becomes legally enforceable or integrated into a business contract [7, 24]. For example, in Ethiopia, the EBCS codes are legally enforceable, while in other parts of the world, they are not. However, those countries have their own similar codes.

2.10. Colombia. The Colombian Code, which was initially triggered with the assessment of losses due to the 1999 earthquake in Colombia, showed that $90 \%$ of casualties occurred in non-bamboo homes; this instigates the Association of Structural Engineers in Colombia (AIS) to study the mechanical properties of bamboo. Later in 2002, the Government of Colombia published a paper detailing local bamboo's structural properties and codified their use in oneto two-story buildings. It was arguably the first fully 
developed standard for guidance and design values concerning bamboo as a structural member.

Nevertheless, the 2002 version of Colombian standard chapter E.7 (chapter E.7 is a standard that enables the use of bamboo in structures, provided it is part of a modern bahareque system) limits the role of bamboo (it contains no guidance on beam design, and very limited and prescriptive values for column and connection design) to that of a component within a system. It played an important role in acting as the template for Peru's E.100, Ecuador's NEC-SE-GUADÚA, and the Andean standard [25]. It has also influenced similar developments taking place in Mexico and the Philippines.

In 2010 arguably, the most comprehensive developed standard for structural design with bamboo was the published chapter G.12 within the Colombian NSR-10 [26]. Nevertheless, it only considered the species' Colombian Guadua angustifolia Kunth' and did not include the procedure of connection design value determination and listed unusual moduli of elasticity values. It is arguably the first most comprehensive and developed standard for bamboo's structural design in the world that would allow a user to undertake the complete structural design. It also contains some visual grading guidance, factors of safety, a process to derive characteristic values, mechanical properties, design procedures for beams and columns, some design values for connections, and links to chapter E.7, shear wall strength values.

Even though more recent efforts within ISO and backed by INBAR have taken the lead in codifying bamboo for structural design elements, two codes stand out in this field: the Colombian design code chapters E.7 and G.12 [26].

2.11. India. The National Building Code of India, 2005 developed a Code of Practice for Bamboo Design (Part 6 Structural Design-Section 3-Timber and Bamboo: 3B Bamboo), which was based on work done at the Forest Research Institute in Dehra Dun, the Indian Plywood Industries Research and Training Institute in Bangalore, INBAR documents, and the following Indian Standards: 6874:1973 Method of test for round bamboo, 8242:1976 Method of test for split bamboo, 9096: 1979 Code of practice for preservation of bamboo for structural purposes, and 13958 : 1994 Specification for bamboo mat board for general purposes.

Section 3B of the National Building Code of India (NBCI) specifies strength limits for three classes of bamboo, which reflect species found in India. Although some examples of bamboo joints and connections are given, there is no detailing on measurements and capacity [27]. Although the identification of bamboo species based on anatomical appearance for structural purposes is not yet perfected, it is recommended that experienced sorters use morphological valuation to identify full-standing culms. A total of twenty (20) Indian bamboo species were evaluated systemically, with 16 bamboo species being recommended for structural applications in round form. The code also recommends that bamboo must be mature for at least four years, be used for at least six weeks of the felling duration, and be processed under IS 9096 as a certification requirement for structural construction.

2.12. Peru. The earthquake in Peru in 2007 prompted additional research into the engineering properties and values of bamboo for housing, and the country later passed bamboo legislation in 2012. The standard discusses the design and construction of seismic-resistant structures using bamboo. Other codes and standards, such as the Colombian Code and ISO standards for bamboo construction, are also referred to for developing the standard. Modified versions of the structural design calculations from the Colombian Code (although not as detailed as their original source) and construction design from the Ecuadorian Code are included [1].

2.13. Ecuador. Ecuadorians issued and legislated a code of practice for bamboo construction in 2017, owing to the seismic events of 2016, such as Colombian 1999 and Peruvian 2007 [28]. Chapter 17 of Norma Ecuatoriana de la Construcción on the utilization of Guadua angustifolia Kunth in construction addresses processing, selection, construction, and maintenance. Unlike the Colombian norms on joints and preservation $[8,21]$, the Ecuadorian [22] did not include the design calculations; however, it described the process.

\section{Conclusions and Future Remarks}

Bamboo has a long and well-established application as an alternative, sustainable construction material, though its use for a structural design element is restricted. This is mainly because of the absence of enough design standards and codes of practice to offer a complete and thorough guideline. As a result, the industry has remained hesitant to use such vernacular materials to construct structural elements. As the design guidelines were inadequate, the application of bamboo as an engineering material was primarily based on established practical traditions, intuitions of forbears, and engineering experience.

Despite there are existing design and testing standards for full culm bamboo $[18,19,29]$, they do not provide the foundation from which builders, engineers, and architects can design and construct [11]. Furthermore, the bamboo building designers still do not have any handbooks with a clear set of codes of practice and standards that assist in a full detailed design. They usually use their own experience to design a bamboo building. If we ask people how they design a bamboo building, they often answer that they can do it because they have some experience, but they have no specific knowledge. Those who have experience with designing bamboo buildings are confident of their design capabilities [3].

It is a constraint for the progress of bamboo as an engineering and building material in developing countries. National standards that rectify this problem can open the way for engineers and designers to work with bamboo. Hence, developing such standards and codes would pave a way to promote the use and applications of the material like 
bamboo in the construction industry by reaping its competitive advantages through ongoing studies and testing protocols. For example, bamboo grows naturally in Africa, Asia, America, and Oceania, and more than 1200 bamboo species have been catalogued [10,30].

It is likely to have misleading conclusions from some widely available published data on bamboo strength as the strength and characteristics vary from species to species. On top of that, the interpretations of the testing values of different methodologies are likely to have different results. For instance, the Indian standard IS 15912 states that optimum moisture content or fiber saturation point for most bamboos is at around 25 percent; however, there will certainly be a probability of deviation from this test for some species. The National Building Code of India, 2005, only examined 20 species of bamboo for their structural use performance and categorized 16 species of bamboo; the Colombian Code of practice only considered the species' Colombian Guadua angustifolia Kunth. Taking the abovementioned examples as a reference and designing structural elements for Ethiopian indigenous species could lead to a compromised structural performance; hence, there is a need to develop customized and contextualized design standards and codes of practice. However, taking prior standards like the ISO standards and codes of practices will help to develop such documents.

The brief review of international bamboo structural elements design standards, and codes of practice provides a way forward for further bamboo building standardization. The review shows that many of the current standards and codes refer to ISO standards that have proved to be inadequate for general use. The ISO standards provide the basis for bamboo design but must be revised and extended to reflect increased research on test methods and material characterization, as well as new structural bamboo products.

\section{Data Availability}

The data used to support the findings of this study are available from the corresponding author upon request.

\section{Conflicts of Interest}

The authors declare that they have no conflicts of interest regarding the publication of this study.

\section{Acknowledgments}

The researchers acknowledge the technical support of Addis Ababa University.

\section{References}

[1] A. Gato'oB. Sharma et al., "Sustainable structures: bamboo standards and building codes," Proceedings - Institution of Civil Engineers, vol. 167, no. 5, pp. 189-196, 2014.

[2] F. Mardjono, A Bamboo Building Design Decision Support Tool, A traditional bamboo house in Java, Indonesia, 2002.

[3] R. Culzoni, Características dos bambus e sua utilização como Material Alternativo no Con- creto, PUC-Rio, Janeiro, RJ, Brasil, 1986.
[4] O. Lopez, Bambu su Cultivo y Aplicationes en: Fabricación de Papel, Ingenieria, Artesania, Estu- dios técnicos Colombianos Ltda, Cali, Colombia, 1974.

[5] H. Sharma and K. Reddy, Geoenvironmental Engineering: Site Remediation, Waste Containment, and Emerging Waste Management Technologies, John Wiley \& Sons, Hoboken, New Jersey, United States, 2004.

[6] J. J. A. Janssen, Designing and Building with Bamboo, Technical University of Eindhoven, Eindhoven, Netherlands, 2000.

[7] Erico, "nvent," 2018, https://blog.nvent.com/erico-what-isthe-difference-between-a-code-standard-regulation-andspecification-in-the-electrical-industry.

[8] A. M. Blayse and K. Manley, "Key influences on construction innovation," Construction Innovation, vol. 4, no. 3, pp. 143-154, 2004.

[9] B. R. Ellingwood, "Probability-based codified design: past accomplishments and future challenges," Structural Safety, vol. 13, no. 3, pp. 159-176, 1994.

[10] S. Kaminski, A. Lawrence, D. Trujillo et al., "Structural use of bamboo . Part 3 : design values,” Structural Engineer, vol. 94, no. 12 , pp. $42-45,2016$.

[11] K. A. Harries, B. Sharma, and M. Richard, "Structural use of full culm bamboo: the path to standardization," International Journal of Architecture, Engineering and Construction, vol. 1, no. 2, pp. 66-75, 2012.

[12] Inbar, Value Chain Analysis and Market Assessment of Bamboo Products in Ethiopia, INBAR, Beijing, China, 2018.

[13] Inen, Chapter 17 - Utilizacio'n de la Guadua Angustifolia Kunth en la Construccio'n. Norma Ecuatoriana de la Construccio' $n$, INEN, Quito, Ecuador, in Spanish, 2011.

[14] Icg, Reglamento Nacional de Edificaciones, Section III. 2 Code E100 - Diseño y construccio'n con bambu', ICG, Lima, Peru, (in Spanish), 2012.

[15] M. Prc, "JG/T 199," Testing Method for Physical and Mechanical Properties of Bamboo Used in Building, PRC MoC, Beijing, China, 2007, in Chinese.

[16] Bis, Section 3, Timber and Bamboo: 3B, National Building Code of India, New Delhi, India, 2010.

[17] Bis, (Bureau of Indian Standards), IS 6874-2008: Method of Tests for Round Bamboos, BIS, New Delhi, India, 2008.

[18] Iso, ISO 22157-1: 2004 (E): Bamboo - Determination of Physical and Mechanical Properties - Part 1: Requirements, ISO, Geneva, Switzerland, 2004b.

[19] Iso, ISO 22156: 2004 (E): Bamboo - Structural Design, ISO, Geneva, Switzerland, 2004a.

[20] C. Icontec, "Norma Te'cnica Colombiana (NTC) 5407: uniones de estructuras con Guadua angustifolia Kunth," ICONTEC, Bogota', Colombia, 2006.

[21] Icontec, NTC 5525: Me'todos de Ensayo para Determinar las Propiedades $\mathrm{Fl}^{\prime}$ 'sicas y Meca'nicas de la Guadua angustifolia Kunth, ICONTEC, Bogota', Colombia, 2007.

[22] E. Inen, INEN 42: Bambu' Cã̃a Guadua, INEN, Quito, Ecuador, in Spanish, 1976.

[23] Astm, ASTM D5456: Standard Specification for Evaluation of Structural Composite Lumber Products, ASTM International, PA, USA: West Conshohocken, 2013.

[24] Hasa, "Explore," 2016, https://pediaa.com/differencebetween-code-and-standard/.

[25] Inbar, "Norma Andina para diseño y construcción de casas de uno y dos pisos en bahareque encementado," Red Internacional para el Desarrollo del Bambú y el Ratán, Oficina para América Latina y el, Caribe, Quito, Ecuador, 2015.

[26] D. Trujillo, "Prospects for a method to infer non-destructively the strength of bamboo: a research proposal," in Proceedings 
of the 3rd International Conference on Sustainable Construction Materials and Technologies, Kyoto, Kyoto, Japan, Paper E074, Kyoto, Japan, August 2013.

[27] B. Sharma, Seismic Performance of Bamboo Structures Dissertation, University of Pittsburgh, Pittsburgh, PA, USA, 2010.

[28] D. Witte, "Structural bamboo building codes: catalysts for industry, research, and construction Technology," Technology| Architecture + Design, vol. 3, no. 1, pp. 50-64, 2019.

[29] Iso, ISO 22157-2: 2004 (E): Bamboo - Determination of Physical and Mechanical Properties - Part 2: Laboratory Manual, ISO, Geneva, Switzerland, 2004c.

[30] E. Zea Escamilla and G. Habert, "Environmental impacts of bamboo-based construction materials representing global production diversity," Journal of Cleaner Production, vol. 69, pp. 117-127, 2014. 